\title{
“Tertawa” dalam Budaya Jawa: Sebuah Kajian Antropologi Bahasa
}

\author{
Hendarto Supatra \\ Fakultas Ilmu Budaya Universitas Diponegoro \\ Email: hendartosupatra53@gmail.com
}

\begin{abstract}
Human being is the only God's creation that can tertawa (laugh) and tersenyum (smile). People tertawa or tersenyum when they want to express their happiness, it is at least according to Kamus Besar Bahasa Indonesia (2011) or laugh according to The Macquarie Dictionary (1991). But sometime people also tertawa or tersenyum when they experience serious bad luck. Often people has no choise but tertawa or tersenyum as a way to show their feeling which they don't think possible to express in verbal language. Tertawa and tersenyum phenomena are universal. But every language has their unique way to symbolize them. In Indonesian spoken by people with the Javanese culture as their background use severel words and phrases as the synonyms of tertawa to encode many difference experiences which are still with in the concept of tertawa. The goal of this research is to describe the form and behavior the word tertawa and all it's synonyms and to find out the reasons behind the use of the words or people mean when they use the words. To get the goal fulfilled this research used linguistic anthropology, it's theories and methods.
\end{abstract}

Keywords: linguistic anthropology, thick description, laugh word, laugh phenomenon.

\section{Intisari}

Manusia adalah satu-satunya ciptaan Tuhan yang bisa tertawa atau tersenyum, untuk mengekspresikan isi mindanya, yang biasanya berupa kegembiraan. Demikianlah itu, setidaknya menurut KBBI (2011) dan menurut Macquarie Dictionary (1991) untuk kata laugh. Akan tetapi dalam kenyataannya, orang juga tertawa ketika mengalami nasib buruk atau ketidakberuntungan yang serius dan itu terlalu muskil untuk diekspresikan secara verbal. Tertawa dan tersenyum adalah fenomena universal, akan tetapi fenomena tersebut direpresentasikan secara berbeda-beda pada tiap-tiap bahasa. Dalam bahasa Indonesia kata tertawa yang digunakan oleh penutur yang berlatar belakang budaya Jawa, tentu saja, mempunyai cirri tersendiri. Artikel ini memuat hasil deskripsi keunikan kata tertawa dan sinonimnya. Dengan menggunakan interpretasi lulam (luas mendalam) maka kekhasan kajian antropologi dengan bahasa sebagai objeknya, terpenuhilah tuntutan disiplin antropologi bahasa.

Kata kunci: linguistik antropologi, deskripsi lulam, kata tertawa, fenomena tertawa. 


\section{Pendahuluan}

Judul tulisan ini sebagaimana tertera di atas sepertinya bukan kajian bahasa; kajian tentang "tertawa" bukan kata tertawa. Demikianlah tampaknya. Kesan sepintas seperti itu memang tidak sepenuhnya salah. Tertawa memang merupakan fenomena universal yang khas manusiawi yang pada sisi lain juga merupakan wujud ekspresi dari suasana kejiwaan yang khas atau unik pada tiap-tiap masyarakat budaya. Tulisan ini merupakan laporan hasil pengamatan seluk-beluk tertawa yang terekspresikan dalam kata tertawa (bahasa Indonesia) berikut berbagai bentuk turunannya oleh penutur bahasa Indonesia yang berlatarbelakangkan budaya Jawa. Dengan demikian perhatian tulisan ini ada pada kata tertawa dan berbagai perubahan bentuk/maknanya baik dalam level morfologis maupun sintaksis dalam kerangka kajian antropologi. Pendek kata ini adalah kajian antropologi dengan objek kajian berupa kata tertawa dalam kaitannya dengan fenomena tertawa dalam konteks masyarakat Jawa atau lebih kongkritnya bahasa Indonesia dialek Jawa.

Antropologi bahasa (linguistic anthropology) berbeda dengan sosiolinguistik/antropolinguistik, mengkaji bahasa "as the instrument of culture, that is, as the voice, tool, and foundation of any human experience" (Duranti, 1997: 1). Lebih lanjut, masih pada halaman yang sama, Duranti memberi penjelasan sebagai berikut: "Such experience is given meaning by one or more cultural traditions and helps reproduce (and change) such traditions. Hence, the object of study for linguistic anthropology is language as a resource and speaking as practice".

Objek kajian antropologi adalah kebudayaa, yakni system makna yang sangat kompleks dan khas manusiawi. Kekhasan atau keunikan kebudayaan manusia ini sedemikian rupa sehingga dan memang telah terbukti, tidak mungkin didekati dengan menggunakan metode serta teknik yang digunakan dalam ilmu-ilmu alam. Dengan metode ilmu eksata, orang tidak akan memperoleh apa-apa, demikian komentar Geertz (Lihat Pals, 2011: 328). Geertz sangat yakin bahwa fenomena kebudayaan tidak tepat untuk dijelaskan sebagaimana yang lazim dalam ilmu eksata. Alih-alih, untuk itu, Geertz mempercayai metode interpretasi yang tanpa akhir (secara fenomenologis). Metode interpretative ini sudah barang tentu mensyaratkan dilakukannya penelitian kancah. Sampai di sini orang diingatkan bahwa yang dilakukan Geertz sebenarnya melanjutkan tradisi Bronislaw Melinowski (1884-1942). Malinowski adalah salah seorang pencetus antropologi lapangan. 
Salah satu pernyataannya yang kemudian menjadi klasik ialah bahwa,"Suatu teori general harus didasarkan pada studi etnografi yang benar-benar ketat dan khusus, yang memusatkan perhatian pada satu budaya dan membutuhkan waktu ber-tahun-tahun untuk menuntaskannya" (ibid: 332).

Di Amerika Serikat sendiri boleh dikatakan Geertz sependapat dengan para pendahulunya seperti Boas, Kroeber dan Lowie. Tiga orang ini juga sependapat bahwa kata kunci untuk studi antropologi adalah "kebudayaan" yang dalam kaitannya dengan kajian antropologi ini meliputi adat-istiadat, perilaku, symbol, dan institusi-institusi dalam masyarakat. Masyarakat tertentu yang dimaksud di sini dipahami mereka sebagai bagian dari sekian banyak system yang ada. Pembatasan yang sengaja dibuat sedemikian ketat itu dimaksudkan agar peneliti bisa melakukan deskripsi lulam (Luas lagi mendalam) atau thick description menurut istilah Geertz dan bersifat emik bukan ethik.

Sampai di sini peneliti merasa diuntungkan karena objek penelitian ini adalah kata tertawa dalam kaitannya dengan fenomena tertawa dalam bahasa Indonesia yang dituturkan oleh masyarakat Jawa (Tengah) di mana peneliti adalah salah seorang penutur asli dialek tersebut. Apabila tidak demikian maka diperlukan grounded dalam bilangan waktu bertahun-tahun seperti yang dilakukan oleh Geertz yang harus tinggal di tengah-tengah masyarakat Jawa (Timur) lebih dari 5 tahun itu. Langkah Geertz ini hanyalah dimaksudkan agar sang peneliti berhasil menginternalisasi apa yang disebut pola-pola kebiasaan dalam berbahasa yang unik pada tiap-tiap bahasa yang dimiliki oleh anggota masyarakat bahasa yang toh cenderung kurang disadari oleh anggota masyarakat tutur tadi. Sehingga, Woolfson dalam artikelnya yang berjudul "Language, Thought, and Culture" (dalam Clark dkk. 1981:46) menulis sebagai berikut: "What is necessary is that we become aware of these patterns by conscious introspection, scientific study, or crosscultural comparison". Dan tentu saja conscious introspection mensyaratakn telah adanya internalisasi pola kebiasaan yang menentukan baik kekhasan gramatika maupun kosakata-kosakata bahasa yang bersangkutan, dan bagi seorang peneliti yang berpengalaman, metode tersebut sama sekali tidak bertentangan prinsip dasar interpretasi.

Satu hal lagi yang perlu diperhatian sehubungan dengan penelitian ini adalah pendapat Ruth Benedict dalam bukunya yang berjudul Pattern of Culture (1934) ialah bahwa kebudayaan merupakan semacam sikap sekelompok orang, kepribadian komunal 
yang terbentuk dari pemikiran dan pemahaman individu-individu. Konsekuensinya ialah tidak adanya kategori objektif dalam penelitian social (Bandingkan Pals, hal. 334). Oleh karenanya, interpretasilah satu-satunya metode yang mestinya digunakan dan cara kerja yang demikian itu tak lain adalah cara kerja antropologi semiotic.

\section{Bentuk dan Perilaku Kata Tertawa}

Sebelum memasuki pembahasan kata tertawa dalam kaitannya dengan fenomena tertawa terlebih dahulu akan dibahas kata tertawa dalam kajian linguistis dengan memperhatikan bentuk dan perilaku kata tertawa. Dengan perilaku, yang dimaksudkan di sini tidak lain adalah relasi paradigmatic dan relasi sintakmatig kata tertawa.

Kata tertawa berpadanan dengan kata ngguyu dalam bahasa Jawa yang terdiri dari prefix N- (ater-ater hanuswara) dengan bentuk dasar guyu. Jadi ngguyu merupakan kata polimorfemis. Sementara itu kata tertawa sepertinya juga kata polomorfemis yang terdiri dari prefix ter- dan bentuk dasar tawa. Akan tetapi agaknya tidak demikian halnya. Kata tertawa ada kalanya bervariasi bebas dengan kata ketawa maupun tawa. Kalimat berikut ini gramatikal dan berterima.

(1) $\left.\begin{array}{l}\text { Ketawanya } \\ \text { Tawanya }\end{array}\right\}$ melegakan banyak orang.

Adanya bentuk tawa dan prefix ter- tidak membuktikan bahwa di sini orang berhadapan dengan bimorfemik, sebab di satu pihak terdapat bentuk-bentuk turunan seperti menertawai, menertawakan, ditertawai, ditertawakan, dsb. sementara itu tidak ada bentuk *menawai, *menawakan, *ditawai, *ditawakan. Agaknya adanya bentuk tawa yang memang merupakan varian tertawa itu justru berasal dari tertawa. Di sini telah berlaku prinsip ekonomi bahasa. Bukti lain bisa diketengahkan di sini dalam hal bentuk-bentuk seperti terlihat, terdengar, tercium, terjangkau, terpukul, dst. yang mirip dengan bentuk tertawa itu, tidak bisa diturunkan menjadi bentuk-bentuk *menerlihat, *menerdengar, *menercium, *menerjangkau, *menerpukul, dst. Yang ada adalah melihat, mendengar, mencium, menjangkau, dan memukul. Adapun perihal bentuk ketawa yang di sini dianggap bukan bentuk utama didasari oleh argumentasi bahwa bentuk tersebut tidak mempunyai 
bentuk turunan seperti *mengetawai, *mengetawakan, ?diketawai, ?diketawakan. Dua bentuk yang terakhir itu setidaknya untuk saat ini meragukan.

Kata tertawa termasuk ke dalam kategori kata verba jenis intransitive. Dalam hal ini sama dengan ngguyu dalam bahasa Jawa. Sebenarnya tertawa (bukan kata tertawa) bisa dikatagorikan 'melakukan tindakan' tetapi juga bisa dikatakan 'dalam keadaan'. Dalam konteks yang terakhir ini subjek, bisa dikatakan, tidak sedang melakukan tindakan. Bertolak dari nosi semacam ini tertawa sepertinya termasuk kategori adjektiva. Tegasnya, kata tertawa diyakini sebagai yang termasuk ke dalam kategori di antara verba dan adjektiva. Ya, agaknya demikian.

Kata tertawa mempunyai bentuk-bentuk turunan seperti menertawai, menertawakan, ditertawai, ditertawakan, tertawaan, tertawanya, tertawa-tawa (tertawatertawa). Berikut ini contoh dalam pemakaian.

(2) Arman menertawai tingkah laku adiknya yang baru berumur dua tahun itu.

(3) Deni menertawakan temannya yang suka berlagak sok tahu itu.

(4) Tingkah yang lucu itulah yang ditertawainya.

(5) Dasar dungu, dia justru bangga ketika ditertawakan orang.

(6) Sekarang baru dia sadari bahwa dirinya menjadi tertawaan orang banyak.

(7) Tertawanya lepas, melegakan orang banyak.

(8) Sejak tadi dia tertawa-tawa melulu, tidak segera mulai bekerja.

Bahwa kata tertawa itu termasuk kategori verba bisa dibuktikan dengan kecenderungannya berada pada posisi predikat meskipun bukan berarti tanpa eksepsi.

(9) Para penonton, hampir tanpa kecuali, tertawa ketika Tukul menari dalam acara....

(10) Tertawa itu sehat.

Tertawa pada kalimat (9) berada pada posisi predikat sedang pada kalimat (10) merupakan pengisi slot subjek. Tertawa pada (10) sebenarnya sudah bukan lagi verba melainkan nomina, jadi telah mengalami proses morfologis jenis modifikasi zero .

Berada pada posisi predikat sebenarnya baru mengindikasikan bahwa kata tersebut termasuk verba. Mengapa demikian? Ya, karena adjektiva juga bisa menduduki posisi predikat. Data berikut ini, yakni perilaku kata tertawa dalam tataran frasa meyakinkan orang bahwa tertawa memang verba. 
(11) Para penonton sudah tertawa semua.

(12) Mereka kedengaran sedang tertawa.

(13) Kami sepakat untuk tidak akan tertawa besuk ketika dia manggung.

Sebagai pengisi predikat kata tertawa bisa diekspansi ke kiri dengan menggunakan kata sudah/telah, sedang, dan akan. Akan tetapi ada kecenderungan, di masa belakangan ini, bahwa kalimat berikut ini juga mulai bertrima.

(14) Adik memang tertawa juga, kakak lebih tertawa, dan sayalah yang paling tertawa.

Ekspansi ke kiri dengan menggunakan kata lebih dan paling menunjukkan cici adjektiva.

Demikianlah, bahwa tertawa memang bisa diartikan sebagai 'dalam keadaan' atau pun 'melakukan tindakan'. Perilaku yang demikian ini agaknya tidak terdapat pada kata laugh dalam bahasa Inggris yang pasti sudah kekategorikataannya, yakni verba intransitive.

\section{Kata Tertawa dan Maknanya}

Tertawa adalah kata yang secara semiotic juga disebut tanda atau symbol. Dalam pembicaraan tentang makna, sehubungan dengan tanda, orang tentu teringat pada tiga tokoh yang bisa disebut sebagai pelopor semiotic, yakni C.S. Peirce, Ogden dan Richards, serta Saussure. Tiga orang yang pertama dikenal sebagai pelopor semiotic di Amerika sedangkan yang disebut terakhir yang juga dikenal sebagai bapak linguistic itu bisa dikatakan sebagai pelopor semiotika di Eropa. Peirce (Lihat Fiske, 1982: 24) menulis perihal tanda dan maknanya sebagai berikut.

A sign is something which stand to somebody for something in some respect or capacity. It addresses somebody, that is, creates in the mind of that person an equivalent sign, or perhaps a more developed sign. The sign which it creates I call the interpretant of the first sign. The sign stands for something, its object.

Jadi, menurut Peirce terdapat tiga elemen makna yakni sign atau tanda atau symbol, objek, dan interpretan. Sebagai konsekuensinya kajian kemaknaan suatu tanda dapat dipilah menjadi dua yakni makna sehubungan dengan relasi antara tanda dengan objeknya dan makna sehubungan dengan relasi antara tanda dengan interpretannya. 
Kata tertawa adalah sebuah tanda yang merujuk ke dua jenis realitas (objek) yang berkaitan satu dengan yang lain akan tetapi berbeda. Tertawa sebagai realitas yang dirujuk oleh kata tertawa bisa berupa suara (khas) yang dihasilkan mulut manusia, yang dalam tulisan (gambar dari tertawa) disimbuli dengan $H a$...ha ...ha ...ha atau Hi...hi ...hi ...hi atau He...he...he...he. Realitas tertawa juga bisa berupa ekspresi wajah tertentu yang ada kalanya sama sekali tanpa suara. Tertawa sebagai atau yang berupa ekspresi wajah saja itu biasanya merupakan tertawa ringan akan tetapi tertawa keras pun bisa jadi tanpa suara ketika orang yang tertawa itu sengaja untuk tidak menghasilkan suara karena takut menyinggung perasaan orang. Yang terakhir ini tak jarang masih disertai gerak tangan yang menutupi mulutnya. Termasuk ke dalam jenis tertawa tanpa suara ini adalah tersenyum yang dalam bahasa Jawa masih dibedakan lagi antara mesem 'tersenyum', menjeb dan mlerok. Menjeb dan mlerok sepertinya tidak dijumpai padanannya dalam bahasa Indonesia. Kekayaan semacam ini mestinya dipungut saja ke dalam bahasa Indonesia.

Fenomena tertawa, dalam bahasa Indonesia dialek Jawa, yang tentunya entah banyak atau sedikit berbeda dengan dialek bI yang berlatarbelakang budaya Papua misalnya, dapat dibedakan lagi menjadi terbahak-bahak, terkekeh-kekeh, terkikik-kikik, terpingkal-pingkal, sedangkan tersenyum itu sendiri di samping menjeb dan mlerok tadi masih ada merenges dan meringis.

Tertawa terbahak-bahak adalah jenis tertawa dengan suara keras dan besar (Bandingkan KBBI, Hal. 1412) bedanya dengan terkekeh-kekeh dan terkikik-kikik ialah bahwa yang disebut terakhir itu suaranya lebih kecil di samping realitasnya tawa terbahakbahak itu mengandung vocal /a/ sedangkan yang lain vocal /e/ dan /i/. Jadi penyebutan ketiganya itu dalam bI termasuk onomatopei (ikonik). Dalam realitasnya bisa saja terjadi semula orang terbahak-bahak tetapi kemudian berubah menjadi terkekeh-kekeh, dan akhirnya terkikik-kikik, atau sebaliknya. Adapun terpingkal-pingkal itu mirip dengan terbahak dan sebagainya itu. Bedanya, dengan kata terpingkal-pingkal itu hendak diinformasikan bahwa orang yang tertawa itu nyaris kehilangan control diri sehingga terkadang sampai mengeluarkan air mata dan kalau berlanjut bisa-bisa orang mengalami kejang perut.

Tersenyum adalah ekspresi wajah sebagai varian dari tertawa yang tidak bersuara melainkan dengan mengembangkan bibir sedikit (Bandingkan KBBI, hal. 1277). Menjeb 
(bJ) yang tidak jarang digunakan dalam berbahasa Indonesia itu kurang lebih sama artinya dengan tersenyum atau mesem (bJ) hanya saja di dalam menjeb itu ada unsur 'mencibir'. Mlerok juga masih bisa digolongkan ke dalam jenis tersenyum yakni jenis tersenyum yang 'mengekpresikan perasaan kurang senang'. Merenges adalah tersenyum yang tidak tulus (di dalam hati sebenarnya tidak tersenyum), dan meringis adalah tersenyum yang disertai dengan ekspresi kesakitan.

\section{Tertawa/Tersenyum dan Maksudnya}

Perihal bentuk (morfologis) dan perilaku (sintaktis) kata tertawa termasuk ke dalam kajian relasi antara kata tersebut dengan tanda atau kata lainnya. Terdapat dua jenis relasi antartanda yakni relasi paradigmatik atau in absensia dan relasi sintakmatik atau in praesensia. Perihal relasi antara kata tertawa dan maknanya termasuk ke dalam kajian relasi antara kata tertawa dengan realitas atau objek yang dirujuknya. Relasi tanda dengan objeknya sebenarnya bersifat tidak langsung. Tanda atau pun kata berelasi langsung dengan interpretan yakni berupa konsep dalam benak penuturnya. Konsep atau interpretan ini berelasi langsung dengan realitas atau objek yang dirujuk oleh tanda. Jadi interpretan itu terletak di antara tanda dengan objek.

Di samping dua pokok kajian utama dalam semiotika dalam kaitannya dengan kajian tentang tanda tsb. yakni relasi antara tanda dengan tanda, dan relasi antara tanda dengan maknanya, masih ada satu lagi pokok kajian utama yakni relasi antara tanda dan manusia atau sang pengguna tanda yang tentu saja berkaitan dengan latar belakang social budayanya. Di dalam kajian yang paling akhir itu orang sudah masuk ke wilayah 'maksud'. Ada ungkapan yang sangat tepat berbunyi sebagai berikut: " kata mempunyai makna sedangkan manusia mempunyai maksud'.

Apakah maksud tertawa itu? Atau, mengapa manusia tertawa? Terhadap pertanyaan yang tidak mudah dijawab ini Mangunwijaya (1995: 37) menyajikan buah renungannya demikian: " Ternyatalah bahwa justru pada saat-saat jiwa meluap dan raga jasmani terlalu terbatas untuk memuat rasa, pecahlah tangis maupun ketawa... pendeknya bila kita sedang macet atau menyerah pada suatu banjir persoalan...: menangis atau tertawa”. 
Pada umumnya orang berpendapat bahwa tertawa itu terkait dengan suasana hati gembira, senang, geli, dsb. dengan suara berderai (Lihat KBBI, hal. 1412) sedangkan lawannya adalah menangis yang selalu dikaitkan dengan lawan dari gembira dsb. tadi. Bahwa yang demikian itu cenderung benar memang iya tetapi tidak sepenuhnya benar. Ada kalanya orang tertawa justru pada saat berada dalam pengalaman yang sangat pahit, yang demikian itu tidak jarang ditampilkan dalam film, drama panggung. Orang juga bisa menangis justru di dalam puncak kegembiraan seperti pada saat menjuarai All England misalnya atau memenangkan hadiah mobil dalam suatu acara di TV.

Tertawa dan menangis memang khas manusiawi. Bayi manusia yang baru saja lahir ditunggu-tunggu tangisnya dan diharap-harap, beberapa hari kemudian, tertawanya. Di samping alasan umum atau maksud umum sebagaimana disimpulkan oleh Rama Mangun di atas, masih ditemukan berbagai maksud ketika orang tertawa berikut segenap varian tertawanya.

Tertawa merupakan ekspresi suasana jiwa atau batin seseorang. Ada tertawa yang mengekspresikan kepolosan sehingga orang bisa membaca atau menangkap sikap batin yang tidak berbeda dengan yang terpancar lewat ekspresi wajah. Tertawa demikian adalah tertawa lepas. Jenis tertawa ini terdapat pada anak-anak yang memang belum bertopeng. Tentu saja tawa yang demikian juga didapati pada orang-orang dewasa tertentu yang memang cenderung blak-blakan (ora njaba njero bahasa Jawanya) yang demikian itu dilabeli tertawa raja/ratu. Ketawa atau tertawa jenis ini seperti tertawa anak-anak digemari orang sebab mendatangkan kelegaan orang yang mendengarnya. Lawan dari jenis tertawa ini adalah tertawa palsu. Orang yang tidak terlalu bodoh tentu bisa merasakan suara yang dibuat menyerupai suara tertawa tetapi sebenarnya bukan tertawa sebab sesungguhnya orang yang dimaksud tidak tertawa. Tertawa palsu meskipun kurang menyenangkan, tidaklah selalu negative. Tertawa ini bisa saja dimaksudkan untuk menjaga kontak atau hubungan baik tetapi tertawa palsu juga digunakan untuk mencibir orang.

Ada kalanya orang tertawa terbahak-bahak/terkekeh-kekeh/terkikik-kikik sedemikian tak terkendali dan tak perduli dengan lingkungan, termasuk mereka yang karena jaraknya cukup jauh sehingga orang tidak mengerti alasan tawa tadi, sampai-sampai menimbulkan reaksi yang tidak simpati. Yang demikian itu disebut orang tertawa gila yang sering diasosiasikan dengan orang tak berpendidikan atau urakan dalam bahasa Jawa. 
Pada sisi lain memang bisa dikatakan bahwa tertawa gila ini menandai jiwa orang-orang yang bebas merdeka dari berbagai ikatan belenggu adat. Tertawa gila ini cenderung dilakukan oleh laki-laki di pasar di antara para kuli panggul misalnya, di bengkel sepeda motor atau di lingkungan para tukang dan pembantu tukang bangunan. Dalam wewarah klasik/kuna di masyarakat Jawa atau Nusantara ini didapatkan ungkapan: "Si bodoh tertawa terbahak-bahak sedangkan si pandai diam tersenyum". Di sini tertawa telah dijadikan ukurang atau cerminan budi pakerti seseorang. Bertolak dari hal yang demikian inilah muncul label untuk tertawa ini yakni tertawa dungu.

Tertawa terkendali biasanya memang bermuatan maksud-maksud tertentu. Misalnya adalah tertawa yang dimaksudkan untuk menjaga admosfir percakapan agar menyenangkan; tertawa manis misalnya. Tertawa manis ini senilai dengan basa-basi yang tidak menyembunyikan maksud buruk. Ada kalanya orang juga tertawa meskipun sebenarnya orang tadi tidak senang atau tidak setuju dengan ucapan atau tingkah laku mitra tuturnya. Misalnya ketika jelas-jelas mitra tutur tadi telah menyindirnya. Tertawa yang memuat arti ketidaksenangan atau ketidaksetujuan itu bisa disebut tertawa kecut atau masam. Lebih tinggi tingkatannya dari tertawa kecut ini adalah tertawa sinis. Tertawa sinis bisa disertai dengan rasa dendam kesumat atau kebencian yang sangat mendalam. Aneh memang tetapi benar-benar ada tertawa yang dibarengi dengan ekspperi mata singa yang siap menerkam. Inilah yang disebut orang sebagai tertawa jahat. Termasuk ke dalam tertawa jahat ini adalah tertawa Jin atau Gandarwo, Elo-elo, Banaspati atau tertawa Nenek Lampir dalam film-film horror. Bisa terjadi pula tertawa kecil atau tersenyum itu disertai dengan atau berbarengan dengan ekspresi kepedihan hati, misalnya saja gagal meraih status juara dalam liga sepak bola dunia misalnya. Tertawa atau tersenyum jenis ini disebut orang tertawa/tersenyum pahit.

Sampai di sini kiranya telah dapat disimpulkan bahwa tertawa bisa timbul secara spontan tetapi ada juga yang terkendali atau memang digunakan untuk menjahati orang atau pun untuk membahagiakan orang. Jadi tertawa ternyata mengandung, dalam kadar yang bertingkat, religiusitas. Orang-orang yang telah mengalami pencerahan telah mencapai ketinggian tertentu dalam ketenangseimbangan: tdak lagi memimiliki kebencian atau pun ketakutan, senyum dan tertawanya sangat sugestif untuk orang merasakan kebahagiaan. Pemeluk agama apa pun ketika mereka sungguh-sungguh belajar dan disertai dengan hati 
bersih bisa mempersembahkan senyuman dan tertawanya untuk keluhuran Allah yang MahaLuhur itu.

Tersenyum sebagai tertawa dalam wujud ekspresi wajah juga bisa dirinci lebih jauh menjadi tersenyum lebar, tersenyum simpul, dan tersenyum malu, tersenyum mengoda, tersenyum buaya, tersenyum kambing, tersenyum kucing, dan subjenis tersenyum ini masih bisa bertambah lagi sesuai dengan maksud yang ada. Tersenyum lebar adalah tersenyum yang mengekspresikan kegembiraan yang sesungguhnya. Tersenyum lebar dekat sekali maknanya dengan tersenyum simpul atau tersenyum sedikit tetapi mengekspresikan kesenangan, simpati atau rasa sayang. Tersenyum malu adalah tersenyum yang dibarengi dengan simtom gerak-gerik malu atau wajah yang memerah. Demikian seterusnya, bahwa tersenyum yang mengandung berbagai maksud itu dilabeli dengan kosakata yang mengikutinya. Buaya di dalam tradisi Jawa adalah simbul 'kepalsuan' atau 'kejahatan'; kambing yang suka nyengir itu disepakati sebagai lambang 'mengejek" atau 'mencemooh'; kucing adalah simbul manusia yang suka bermanis-manis/berakrap-akrap tetapi sebenarnya sedang mencari kesempatan untuk mencuri sesuatu, misalnya.

Tersenyum kambing juga disebut merenges atau meringis. Beda antara merenges dengan meringis ialah bahwa di dalam meringis itu ada unsur atau makna 'menahan kesakitan'. Kedua kata yang merupakan sinonim kata tersenyum itu barang kali berasal dari bahasa Jawa sudah mengalami naturalisasi dalam bahasa Indonesia. Kata-kata lain yang agaknya masih dalam proses adalah menjeb dan mlerok. Menjeb adalah tersenyum yang disertai dengan nuansa 'kegenitan' sedangkan mlerok sebenarnya merupakan antonym tersenyum. Mlerok bisa terjadi ketika seseorang dikritik atau dikecewakan di depan orang banyak. Agaknya baik untuk disertakan catatan di sini, bahwa kosakata-kosakata dalam bahasa Jawa yang memperkaya kasanah bahasa Indonesia mesti dimanfaatkan sehingga ketika ranah pemakaian bahasa Jawa semakin sempit karena proses Indonesianisasi yang berjalan dengan baik maka kekayaan bahasa daerah pada umumnya, bahasa Jawa pada khususnya harus dijaga dari kemungkinan terlupakan. Untuk hal-hal yang erat dengan kemodernan bahasa Indonesia diperkaya oleh bahasa-bahasa Internasional sedangkan untuk hal-hal bersangkutan dengan keseharian bahasa Indonesia diperkaya oleh bahasa daerah. 


\section{Tertawa dan Nguyu (bJ): Sedikit Catatan}

Di depan telah disinggung perihal salah satu teknik analisis dalam antropologi bahasa ini yakni memadankan objek kajian dengan padanannya dalam bahasa lain (langue lain) yang idealnya tentu saja dengan satu bahasa serumpun dan satu bahasa yang tidak serumpun meskipun sebenarnya dengan melibatkan semakin banyak bahasa lain sudah tentu akan semakin banyak diperoleh kakhasan bahasa-bahasa itu dalam menandai realitas yang pada hakikatnya sama. Dalam subbab ini hanya akan ditunjukkan kekhasan kata tertawa ketika dibandingkan dengan padanannya dalam bJ, pun sebatas beberapa catatan saja. Penelitian yang mendalam untuk pokok ini pasti akan membuahkan hasil yang tidak sederhana dan memerlukan jumlah halaman yang banyak juga.

Di depan juga telah disinggung perihal perbedaan jenis kata tertawa dengan ngguyu. Ngguyu dalam bahasa Jawa berprefiks N- (ater-ater hanuswara) yang sejajar dengan prefix me- tidak perlu diragukan statusnya sebagai verba intransitif. Halnya berbeda benar dengan tertawa yang bisa diekspansi menjadi paling tertawa. Tertawa berada pada posisi antara adjektiva dan verba transitif. Kata ngguyu merupakan morfem kompleks sedangkan tertawa cenderung monomorfemik.

Dalam bahasa Jawa terdapat kata ngguyokake yang berpadanan dengan kata menertawakan yang artinya 'menjadikan sesuatu/seseorang sebagai objek tertawaan' . Akan tetapi, dengan pengamatan yang lebih dalam, akan menjadi jelas bahwa keduanya itu tidaklah sama persis. Berikut ini sebuah contoh dalam kalimat.

(15) Bocah kuwi jan ngguyokake temenanan.

'Anak itu sungguh membuat orang menjadi geli /terangsang untuk tertawa.'

Bukan hanya maknanya yang berbeda, meskipun dalam konteks tertentu, yang jarang digunakan, kata ngguyukake mengandung makna yang sama dengan menertawakan. Misalnya saja dalam kalimat berikut,

(16) Aku krasa yen dewekne iku ngguyokake/nggeguyu awake dewe.

'Aku merasa bahwa dia itu menertawakan kita.'

dalam pengerttian yang berbeda tadi dua kata yang berpadaanan itu berbeda jenis katanya. Ngguyokake dalam kalimat (15) termasuk verba intransitive sedangkan dalam (16) merupakan verba transitif. Bisa jadi atau layak diduga bahwa penggunaan kata ngguyokake dalam kalimat (16) merupakan kasus yang timbul akibat kontak bahasa atau tepatnya 
interferensi yang hanya terjadi di Semarang misalnya atau kota-kota lain yang jauh dari Yogyakarta atau pun Surakarta.

Satu contoh lagi yang menarik untuk diperhatikan bentuk turunan geguyonan yang jelas terkait dengan kata ngguyu itu berpadanan dengan kata bergurau yang dari sudut bentuknya jelas tidak berkaitan dengan kata tertawa. Dan sebagai catatan akhir kata tertawa-tertawa dalam bahasa Jawa bisa berarti ngguyu-ngguyu tetapi juga bisa berarti ngguya-ngguyu yang maknanya tidak sama persis.

\section{Penutup}

Artikel yang disusun berdasarkan pengamatan/penelitian ini sebenarnya masih berada dalam tahap eksploratif yang sungguh pun demikian, mudah-mudahan, telah menyentuh hal-hal yang esensial sehubungan dengan kata tertawa dan fenomena tertawa yang dihayati oleh peneliti sebagai penutur bahasa Indonesia dialek Jawa. Bahasa Indonesia adalah bahasa utama peneliti yang berlatarbelakangkan budaya Jawa.

Ternyata, dari studi yang dilakukan ini, tertawa/tersenyum merupakan saluran penting ketika orang mengalami kesulitan untuk mengekspresikan melulu dengan bahasa bunyi ujar. Pengalaman rasa yang kompleks mesti disimboli dengan sejumlah tanda nonverbal dan di antaranya yang sangat penting karena sifat khas manusiawinya: tertawa/tersenyum dan atau menangis. Oleh karenanya penelitian ini memang terasa kurang lengkap tanpa kajian kata menangis dan fenomena menangis. Tentu saja dengan menggunakan pendekatan antropologi budaya yang mengandaikan dikerjakannya proyek semacam ini berdasarkan dekripsi lulam atau thick description menurut istilah Geertz peneliti dituntut untuk mengembangkan intuisi kebahasaannya di samping kepekaannya terhadap kompleksitas pertandaan dalam budaya yang dihayatinya sehari-hari. 


\section{Daftar Pustaka}

Clark, Virginia P. 1981. Language, Introductory Reading. New York: St. Martin's Press.

Departemen Pendidikan Nasional. 2011. Kamus Besar Bahasa Indonesia. Jakarta: Pusat Bahasa.

Duranti, Alessandro. 1997. Linguistic Anthropology. New York: Cambridge University Press.

Fiske, John. 1982. Introduction to Communication Studies. New York: Mathuen \& Co.

Geertz. Clifford. 1959. Abangan, Santri, Priyayi Dalam Masyarakat Jawa. Jakarta: Pustaka Jaya.

Larson, Mildred L. 1989. Penerjemahan Berdasar Makna: Pedoman untuk Pemadanan Antarbahasa.

Jakarta: Arcan.

Leech, Geoffrey. 1997. Semantik. Surakarta: Sebelas Maret University Press.

Mangunwijaya, Y.B. 1995. Ragawidya, Religiusitas hal-hal sehari-hari. Yogyakarta: Penerbit Kanisius.

Pals, Daniel L. 2011. Seven Theories of Religion. Yogyakarta: IRCiSoD. 